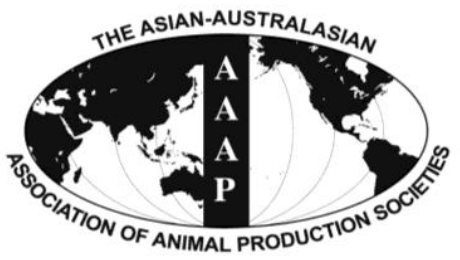

Asian Australas. J. Anim. Sci.

Vol. 26, No. 12 : 1680-1688 December 2013

http://dx.doi.org/10.5713/ajas.2013.13029

www.ajas.info

pISSN 1011-2367 elSSN 1976-5517

\title{
Effects of Trichostatin A on In vitro Development of Porcine Embryos Derived from Somatic Cell Nuclear Transfer
}

\author{
Yeon Ik Jeong ${ }^{1}$, Chi Hun Park ${ }^{1}$, Huen Suk Kim ${ }^{1}$, Yeon Woo Jeong ${ }^{1}$, Jong Yun Lee ${ }^{1}$, Sun Woo Park ${ }^{1}$, \\ Se Yeong Lee ${ }^{1}$, Sang Hwan Hyun ${ }^{1,2}$, Yeun Wook Kim ${ }^{1}$, Taeyoung Shin ${ }^{1}$, and Woo Suk Hwang ${ }^{1}$ * \\ ${ }^{1}$ Sooam Biotech Research Foundation, 64 Kyunginro, Guro-gu, Seoul 152-895, Korea \\ ${ }^{2}$ Laboratory of Veterinary Embryology and Biotechnology, College of Veterinary Medicine, \\ Chungbuk National University, Cheongju 361-763, Korea
}

\begin{abstract}
Many different approaches have been developed to improve the efficiency of animal cloning by somatic cell nuclear transfer (SCNT), one of which is to modify histone acetylation levels using histone deacetylase inhibitors (HDACi) such as trichostatin A (TSA). In the present study, we examined the effect of TSA on in vitro development of porcine embryos derived from SCNT. We found that TSA treatment $(50 \mathrm{nM})$ for $24 \mathrm{~h}$ following oocyte activation improved blastocyst formation rates (to $22.0 \%$ ) compared with $8.9 \%$ in the non-treatment group and total cell number of the blastocysts for determining embryo quality also increased significantly $(88.9 \rightarrow 114.4)$. Changes in histone acetylation levels as a result of TSA treatment were examined using indirect immunofluorescence and confocal microscopy scanning. Results showed that the histone acetylation level in TSA-treated embryos was higher than that in controls at both acetylated histone $\mathrm{H} 3$ lysine 9 (AcH3K9) and acetylated histone H4 lysine 12 (AcH4K12). Next, we compared the expression patterns of seven genes (OCT4, IDI; the pluripotent genes, H19, NNAT, PEG1; the imprinting genes, cytokeratin 8 and 18; the trophoblast marker genes). The SCNT blastocysts both with and without TSA treatment showed lower levels of OCT4, ID1, cytokeratin 8 and 18 than those of the in vivo blastocysts. In the case of the imprinting genes $H 19$ and NNAT, except PEG1, the SCNT blastocysts both with and without TSA treatment showed higher levels than those of the in vivo blastocysts. Although the gene expression patterns between cloned blastocysts and their in vivo counterparts were different regardless of TSA treatment, it appears that several genes in NT blastocysts after TSA treatment showed a slight tendency toward expression patterns of in vivo blastocysts. Our results suggest that TSA treatment may improve preimplantation porcine embryo development following SCNT. (Key Words: Histone Acetylation, Porcine Embryo, Somatic Cell Nuclear Transfer, Trichostatin A)
\end{abstract}

\section{INTRODUCTION}

Animal cloning by somatic cell nuclear transfer (SCNT) has been successfully achieved in various mammalian species. Additionally, it has been proven that the nucleus of differentiated somatic cells can be de-differentiated in oocyte cytoplasm and converted to a totipotent stage by a process termed nuclear reprogramming. However, the overall efficiency of nuclear transfer remains still low (Zhao et al., 2010). The mechanisms underlying nuclear reprogramming are also not entirely clear, although various research studies on this topic are in progress.

The reprogramming processes of the transferred somatic

* Corresponding Author: Woo Suk Hwang. Tel: +82-2-26165658, Fax: +82-2-2616-5672, E-mail: hwangws@ sooam.org Submitted Jan. 11, 2013; Accepted Apr. 13, 2013; Revised Aug. 20, 2013 nucleus in enucleated oocytes include epigenetic events. One of these epigenetic modifications is the acetylation of histones (Turner, 2000), which is known to be a critical factor for successful reprogramming during SCNT (Armstrong et al., 2006). Histone acetylation, which occurs at lysine residues on the $\varepsilon$-amino groups of histones, can alter (decrease) the affinity of histone proteins to DNA sequences by neutralizing the positive charge of the histone tails (Hong et al., 1993). The disruption of higher-order chromatin folding by histone acetylation, in turn, facilitates transcriptional processes (Tse et al., 1998; Horn and Peterson, 2002) because a more extended "open" chromosomal structure can increase accessibility of transcriptional regulatory proteins to their target sequences (Lee et al., 1993; Vettese-Dadey et al., 1996). Moreover, Vogelauer and colleagues have shown that histone acetylation can directly determine the timing of replication 
origin firing (Vogelauer et al., 2002). Some evidence suggests that patterns of histone acetylation during mitosis are maintained from one generation of cells to the next (Turner, 2000); in other words, acetylation-based histone codes may function as an epigenetic mark. Therefore, it appears that successful reprogramming of histone acetylation patterns after SCNT is a crucial factor for turning a differentiated somatic nucleus into a totipotent state.

Histone acetylation is catalyzed by histone acetyl transferases (HATs), whereas the opposing reaction is controlled by histone deacetylases (HDACs). Moreover, the activities of HATs and HDACs regulate the acetylation of histone proteins as well as non-histone proteins such as p53 (Luo et al., 2000), Rb (Chan et al., 2001), and E2F1 (Martinez-Balbas et al., 2000). On the other hand, HDAC activity can be modified by histone deacetylase inhibitor (HDACi). In addition, it has been reported that HDACi has various functions, including the arrest of the mammalian cell cycle by blocking both the G1 and G2 phase (Yoshida and Beppu, 1988), the induction of apoptotic death in some cell lines (McBain et al., 1997; Medina et al., 1997), cell differentiation (Yoshida et al., 1987; Munster et al., 2001), anti-angiogenesis (Mie Lee et al., 2003), and anti-tumor activity (Marks, 2004; Kim et al., 2007). For many years, numerous and diverse types of HDACi have been identified, including short-chain fatty acids such as valporic acid and phenyl butyrate and hydroxamic acid derivatives such as suberoylanilide hydroxamic acid (SAHA), 6-(1,3-dioxo-1H, 3Hbenzo[de]isoquinolin-2-yl)-hexanoic acid hydroxyamide (termed scriptaid), and trichostatin A (TSA). Among these, TSA is the most commonly applied HDACi. Since Kishigami et al. (2006) reported the effects of TSA on both full-term and pre-implantation development after somatic cell nuclear transfer in the mouse (Kishigami et al., 2006), positive effects of TSA on development have been reported in various models including porcine species (Iager et al., 2008; Shi et al., 2008; Zhao et al., 2010).

OCT4, a core transcription factor for pluripotency, is assumed to be a crucial factor controlling mouse, bovine, and porcine preimplantation embryonic development (Kirchhof et al., 2000). ID1, an inhibitor of DNA binding/differentiation, is a member of a family of four proteins known to inhibit activity of transcription factors by controlling their ability to bind DNA. In addition, these proteins have been shown to manage cell fate determination and cell proliferation both in vitro and in vivo (Jankovic et al., 2007). The extraordinary expression of imprinted genes, such as NDN and XIST, has been reported in TSA-treated bovine SCNT blastocysts (Wee et al., 2006). In the mouse, only $4 \%$ of SCNT-derived preimplantation stage embryos recapitulate the expression of imprinted genes, e.g., H19 and Igf2, relative to in vivo-derived blastocysts (Mann et al.,
2003). Cytokeratin 8 and 18, which are trophoblastdetermining genes encoding epithelial-specific intermediate filaments, are enriched in the trophectoderm of blastocysts (Adjaye et al., 2005).

The objectives of this research were as follows: i) to observe whether the development of cloned porcine embryos could be improved by TSA treatment; ii) to analyze the relationship between embryo development and changes in histone acetylation patterns by TSA treatment; and iii) to examine the effects of TSA treatment on the expression pattern of seven genes (OCT4, ID1, H19, NNAT, PEG1, Cytokeratin 8, and Cytokeratin 18).

\section{MATERIALS AND METHODS}

\section{Oocyte collection and in vitro maturation}

Porcine ovaries were gained from a local slaughterhouse and transported to the laboratory within $3 \mathrm{~h}$ of collection. Follicular fluid and cumulus-oocyte complexes (COCs) in follicles were, immediately, aspirated and compact COCs were selected and cultured in modified M-199 (Invitrogen, Carlsbad, CA) supplemented with $10 \mathrm{ng} / \mathrm{mL}$ epidermal growth factor (EGF; Sigma-Aldrich Corp.), $1 \mu \mathrm{g} / \mathrm{mL}$ insulin (Sigma-Aldrich Corp.), $4 \mathrm{IU} / \mathrm{mL}$ of pregnant mare serum gonadotropin (PMSG; Intervet, Boxmeer, Holland), 4 $\mathrm{IU} / \mathrm{mL}$ of human chorionic gonadotropin (hCG; Intervet) and $10 \%(\mathrm{v} / \mathrm{v})$ porcine follicular fluid $(\mathrm{pFF})$. Each well of 4-well dishes (NUNC, Roskilde, Denmark) contained 50 to 80 COCs with $500 \mu \mathrm{L}$ modified M-199 medium, and they were incubated at $39^{\circ} \mathrm{C}$ in a humidified atmosphere of $5 \%$ $\mathrm{CO}_{2}$ in $95 \%$ air. After culturing for $22 \mathrm{~h}$, COCs were washed and transferred to PMSG- and hCG-free M-199 medium, and cultured for another $22 \mathrm{~h}$. At the termination of maturation process, COCs were transferred to HEPESbuffered NCSU-23 medium containing $0.5 \mathrm{mg} / \mathrm{mL}$ hyaluronidase for $1 \mathrm{~min}$ and the cumulus cells were subsequently removed by gentle pipetting for oocyte denuding.

\section{Donor cell preparation}

Primary cell cultures of miniature pig fibroblast cells for somatic cell nuclear transfer (SCNT) were derived from fetuses on day 30 of gestation. Primary cultured cells, at early passage from 2 to 4 , were frozen at $2 \times 10^{5}$ cells/vial for using to SCNT. 3 to 4 days prior to SCNT, cells of 1 vial were thawed at 4-well dish and cultured until $70 \%$ to $90 \%$ confluence.

\section{Somatic cell nuclear transfer}

Somatic cell nuclear transfer process: zonapellucida cutting, enucleation and somatic cell injection, were all accomplished using Nikon TE-2000 micromanipulator system. 
At 42-44 h of IVM, denuded MII oocytes were stained with $5 \mu \mathrm{g} / \mathrm{mL}$ bisbenzimide (Hoechst 33342, Sigma-Aldrich Corp.) for $5 \mathrm{~min}$ to detect both oocyte nucleus and first polar body. And then, we had incised zona pellucida with a fine glass needle right above first polar body to make a slit. Subsequently, the first polar body and some adjoining cytoplasm were extruded through the slit by squeezing method with the same needle (Lee et al., 2003). On all such occasions, it had been checked whether completely extruded or not under very weak ultraviolet light.

Somatic cells were injected into the perivitelline space through cut slit of oocytes with $20 \mu \mathrm{m}$ in diameter injection pipet. Cells were selected according to their size and shape; about $15 \mu \mathrm{m}$ in diameter small cells with a smooth surface (Tao et al., 1999). At transfer of donor cells into enucleated oocytes, careful attention was required to keep a close contact between oocyte cytoplasm and donor cell.

This process was practiced with simultaneous electrical fusion/activation method (Hyun et al., 2003). Cytoplastfibroblast complexes were equilibrated with fusion medium consisting of $0.3 \mathrm{M}$ mannitol solution containing $0.5 \mathrm{mM}$ Hepes, $0.1 \mathrm{mM} \mathrm{CaCl}_{2}$, and $0.1 \mathrm{mM} \mathrm{MgCl}$. Subsequently, these couplets were placed between two electrodes $(3.2 \mathrm{~mm}$ apart) overlaid with fusion medium and then aligned manually. These couplets were fused and activated simultaneously with a single DC pulse of $2.0 \mathrm{kV} / \mathrm{cm}$ for 30 $\mu$ sec using BTX Electro-cell Manipulator 2001 (BTX Inc., San Diego, CA). At $1 \mathrm{~h}$ after fusion/activation, successfully fused embryos only were cultured for experiment.

\section{Trichostatin A treatment}

Trichostatin A (TSA) was obtained from Sigma-Aldrich Corp. (Saint Louise, Missouri) and dissolved in dimethyl sulfoxide (DMSO). Stock solutions of treatment group were prepared as a 200 -fold concentration and stored at $-20^{\circ} \mathrm{C}$. These TSA stock solutions were diluted with culture medium (NCSU-23 supplemented with $0.5 \mathrm{mM} \mathrm{Na-}$ pyruvate and $5 \mathrm{mM}$ lactate) to working concentration immediately before use. TSA has treated with $50 \mathrm{nM}$ for 24 $h$ after SCNT.

\section{In vitro fertilization}

Fresh liquid semen of Yorkshire boar were obtained from Darby Genetics Inc., diluted in $5 \mathrm{~mL}$ Dulbecco's PBS (Invitrogen Corporation) supplemented with 1\% (v/v) Antibiotic-Antimycotic (Gibco, Invitrogen corp.) and centrifuged twice at $350 \times \mathrm{g}$ for $3 \mathrm{~min}$. Then, the sperm pellet was suspended in modified tris-buffered medium (mTBM) to give a concentration of $2 \times 10^{5}$ sperms $/ \mathrm{mL}$. The mTBM consisted of $113.1 \mathrm{mM} \mathrm{NaCl}, 3 \mathrm{mM} \mathrm{KCl}, 7.5 \mathrm{mM} \mathrm{CaCl}_{2}$, $20 \mathrm{mM}$ Tris, $11 \mathrm{mM}$ glucose, $5 \mathrm{mM}$ sodium pyruvate and 8 $\mathrm{mg} / \mathrm{mL}$ BSA. At 42 to $44 \mathrm{~h}$ of maturation culture, oocytes were freed from cumulus cells by repeated pipetting in
$0.1 \%$ hyaluronidase in M-199 medium and washed three times with pre-equilibrated mTBM. The matured oocytes were selected and used for IVF. After washing, 15 to 20 oocytes were placed in $45 \mu \mathrm{L}$ drops of the mTBM (fertilizing drop) covered with pre-warmed mineral oil and $5 \mu \mathrm{L}$ sperm suspension added to each fertilization drop to give a final sperm concentration of $2 \times 10^{4}$ sperms $/ \mathrm{mL}$. After coincubation of gametes for $4 \mathrm{~h}$, the oocytes were washed and transferred into in vitro culture (IVC) medium.

\section{Recovery of in vivo blastocysts}

At the time of onset of estrus in pubertal gilts, they were mated to a fertile boar. After seven days, they were butchered at a local slaughterhouse, and their reproductive tracts were extracted. In vivo blastocysts were collected by flushing of the usterus with PBS including $1 \%(\mathrm{w} / \mathrm{v})$ BSA. Instantly, total mRNA was isolated from collected blastocysts and used subsequently for the synthesis of cDNA.

\section{Nucleus staining to count the total cell number in blastocysts}

It was performed nucleus staining of total cell in blastocysts for assessing the blastocyst quality. In brief, embryos were transferred into $5 \mu \mathrm{g} / \mathrm{mL}$ bisbenzimide (Hoechst 33342, Sigma-Aldrich Corp.) to stain nucleus of the cells for about $10 \mathrm{~min}$, and then fixed with absolute ethanol (Sigma-Aldrich Corp.) at $4^{\circ} \mathrm{C}$ for about $10 \mathrm{~min}$. Fixed and stained whole blastocysts were mounted with glycerol (Sigma-Aldrich Corp.) and assessed for cell number using epifluorescence microscopy.

\section{Immunostaining}

Indirect immunofluorescence was carried out to evaluate and compare the pattern of histone acetylation after SCNT. The embryos were fixed in freshly-prepared $4 \%$ paraformaldehyde in PBS for $1 \mathrm{~h}$. Subsequently, the embryos were washed in PBS containing $0.1 \%$ Tween 20 (TPBS) and then permeabilized with $0.2 \%$ Triton X-100 in PBS for $30 \mathrm{~min}$. Then, the samples were blocked for $45 \mathrm{~min}$ in PBS containing 5\% bovine serum albumin (BSA; SigmaAldrich Corp.) and incubated with primary antibody diluted 1:100 in PBS at $4{ }^{\circ} \mathrm{C}$ overnight. The embryos were washed three times in TPBS and placed in secondary antibody diluted 1:100 in PBS for $30 \mathrm{~min}$ at room temperature. After washing three times in TPBS, the embryos were stained with $5 \mu \mathrm{g} / \mathrm{mL}$ bisbenzimide (Hoechst 33342, Sigma-Aldrich Corp.) for 10 min, mounted with glycerol and sealed with fingernail polish. Observations were carried out, immediately, using a confocal scanning laser microscope (Nikon D-ECLIPSE C1 si). The optical intensity was measured using Image-J software developed at the National Institutes of Health. The primary antibodies were used here 
rabbit polyclonal anti-acetyl-histone $\mathrm{H} 3$ (Upstate cell signaling solution, Lake Placid, NY) and rabbit polyclonal anti-acetyl-histone $\mathrm{H} 4$ at lysine 12 (Upstate cell signaling solution, Lake Placid, NY). The secondary antibody was used fluorescein isothiocyanate (FITC) conjugated goat anti-rabbit IgG (Chemicon international Inc.).

\section{cDNA synthesis and qRT-PCR}

Total mRNA from the single blastocysts was isolated using the Dynabeads mRNA Direct Kit (Dynal Asa, Oslo, Norway). For cDNA synthesis, the isolated mRNA was reverse transcribed using High Capacity RNA-to-cDNA Kit (Applied Biosystems, ABI). Aliquot RT reaction $(20.0 \mu \mathrm{L})$ contains $2 \mathrm{X}$ RT buffer $(10.0 \mu \mathrm{L}), 20 \mathrm{X}$ reverse transcriptase mix $(1 \mu \mathrm{L}$ ), and isolated mRNA sample (up to $9 \mu \mathrm{L}$ ). Reverse transcription was performed at $37^{\circ} \mathrm{C}$ for $60 \mathrm{~min}$, and stop the reaction by heating to $95^{\circ} \mathrm{C}$ for $5 \mathrm{~min}$.

PCR amplification and detection of cDNA was performed using the ABI 7300 Real-Time PCR system (Applied Biosystems, Foster City, CA) with a quantitative real-time PCR kit (DyNAmo HS SYBR Green qPCR Kit, Finnzymes, Finland) under the following conditions: $95^{\circ} \mathrm{C}$ for $15 \mathrm{~min}, 40$ cycles of denaturation at $95^{\circ} \mathrm{C}$ for $15 \mathrm{~s}$, annealing at $60^{\circ} \mathrm{C}$ for $60 \mathrm{~s}$. The PCR reaction mixture $(20$ $\mu \mathrm{L})$ consisted of 100 pmol of forward and reverse primers and $2 \mu \mathrm{L}$ of cDNA. Results for each sample were collected at least three times. All the threshold cycle (CT) values of imprinted genes were normalized relative to that of $\beta$-actin gene, and relative expression ratios were calculated with the $2^{-\Delta \Delta}$ Ct method.

\section{Statistical analysis}

All data were tested for normal distribution and then were analyzed using one-way analysis of variance (ANOVA) after arcsine transformation to maintain homogeneity of variance. Post hoc analysis to identify between-group differences were performed using the least significant different (LSD) test. The same test was used to determine to statistical significance in the cell number of blastocysts among experimental groups without arcsine transformation. All analysis were performed using general linear models in a statistical analysis system (SAS; SAS Institute, version 9.1) program. Differences were considered significant at $\mathrm{p}<0.05$.

\section{RESULTS}

\section{In vitro development following TSA treatment after SCNT}

A total of 802 SCNT embryos and 492 IVF embryos were analyzed. SCNT embryos were randomly distributed across treatment groups, and the experiment was replicated 22 times. As shown in Table 1, cleavage rate of SCNT embryos was lower than IVF embryos regardless of TSA treatment, whereas blastocysts formation rate of TSA treated SCNT embryos was significantly higher than that of non-treated group, and that was similar to the rate of IVF derived blastocyst formation. We also analyzed total cell number counts in blastocysts to determine a blastocyst quality of each experimental groups. Our results showed that TSA treatment increased number of total cells than that of the non-treated SCNT embryos $(\mathrm{p}<0.05)$.

\section{A comparison of histone acetylation levels between TSA- treated and non-treated embryos following SCNT}

Our results show that the acetylation signals of some embryos are not detected at $2 \mathrm{~h}$ following SCNT; however, at $3 \mathrm{~h}$ following SCNT, acetylation signals were detected in most embryos.

As shown in Figure 1, overall histone acetylation levels between TSA treatment and non-treatment groups showed distinct differences at most time points $(\mathrm{A}(\mathrm{a}), \mathrm{B}(\mathrm{a}))$. To confirm these differences, we measured the optical intensity of AcH3K9/14 and AcH4K12 using Image-J software (A(b), $\mathrm{B}(\mathrm{b})$ ). The results show significant differences at all time points in AcH3K9/14 levels between TSA treatment groups and the control $(\mathrm{p}<0.05)$. Results of the AcH4K12 level analysis showed that signals in the TSA treatment groups were significantly higher than those in the control at all time points, excluding the $25 \mathrm{~h}$ group $(\mathrm{p}<0.05)$.

Gene expression profiles among SCNT blastocysts treated with/without TSA and in vivo-derived blastocysts

With respect to gene expression patterns, the pluripotent genes, i.e., OCT4 and ID1, were transcribed at lower levels in SCNT blastocysts compared with their in vivo counterparts. These genes showed slightly higher

Table 1. Effect of trichostatin A (TSA) on development of porcine SCNT embryos

\begin{tabular}{lcccc}
\hline Group & $\begin{array}{c}\text { No. of } \\
\text { cultured embryos }\end{array}$ & $\begin{array}{c}\text { No. of } \\
\text { cleavaged embryos }(\%)\end{array}$ & $\begin{array}{c}\text { No. of } \\
\text { blastocysts }(\%)\end{array}$ & $\begin{array}{c}\text { Mean }( \pm \text { SEM })^{1} \\
\text { cell number }\end{array}$ \\
\hline IVF & 492 & $314(66.6)^{\mathrm{a}}$ & $163(35.9)^{\mathrm{a}}$ & $100.0 \pm 6.1^{\mathrm{ab}}$ \\
SCNT-TSA $(-)$ & 380 & $126(34.5)^{\mathrm{b}}$ & $32(8.9)^{\mathrm{b}}$ & $88.9 \pm 10.8^{\mathrm{a}}$ \\
${\text { SCNT-TSA }(+)^{2}}^{\mathrm{b}}$ & 422 & $180(44.2)^{\mathrm{b}}$ & $90(22.0)^{\mathrm{a}}$ & $114.4 \pm 6.3^{\mathrm{b}}$ \\
\hline
\end{tabular}

${ }^{\mathrm{ab}}$ Values with different superscripts within the same column were significantly different $(\mathrm{p}<0.05)$.

${ }^{1} \mathrm{SEM}=$ Standard error of the mean. ${ }^{2} \mathrm{TSA}$ has been treated with $50 \mathrm{nM}$ for $24 \mathrm{~h}$ after fusion/activation. 
A

(a)

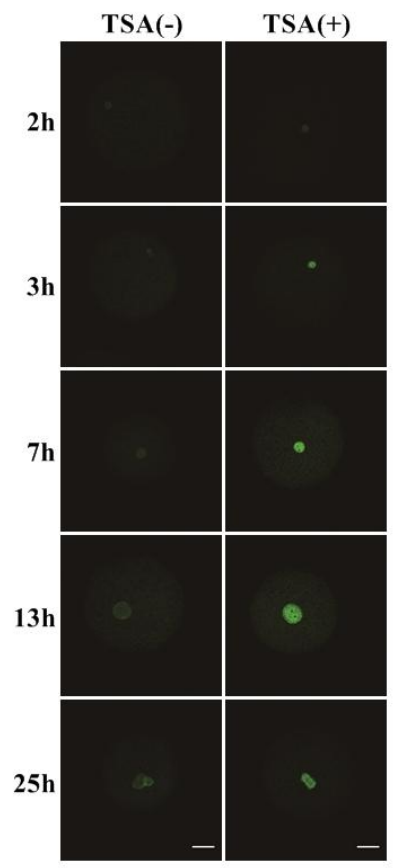

B

(a) (b)

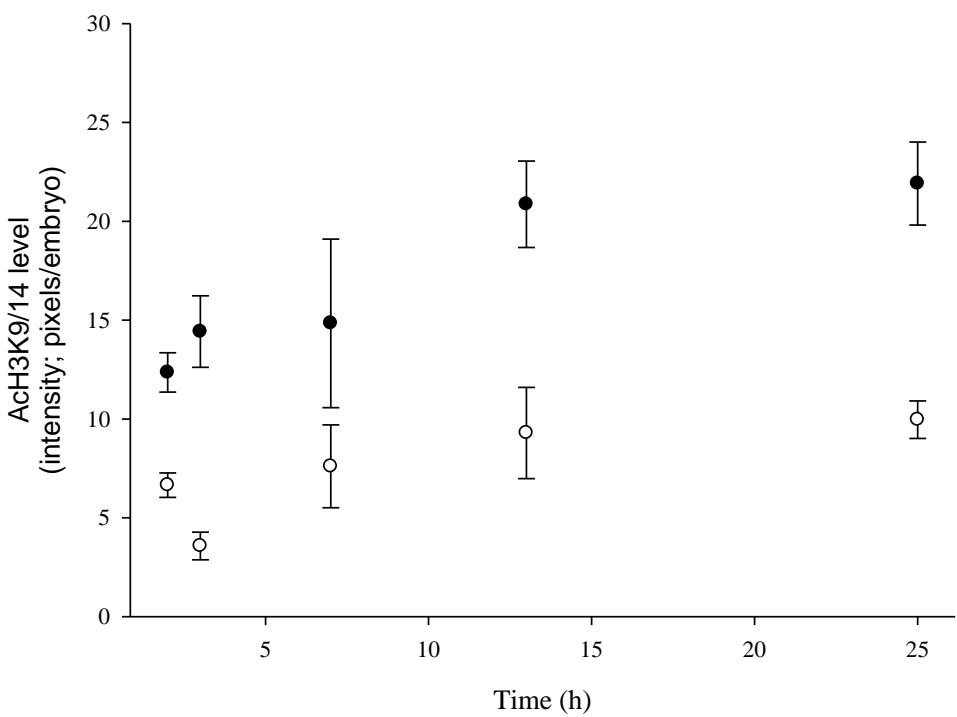

- TSA (+)

- TSA (-)
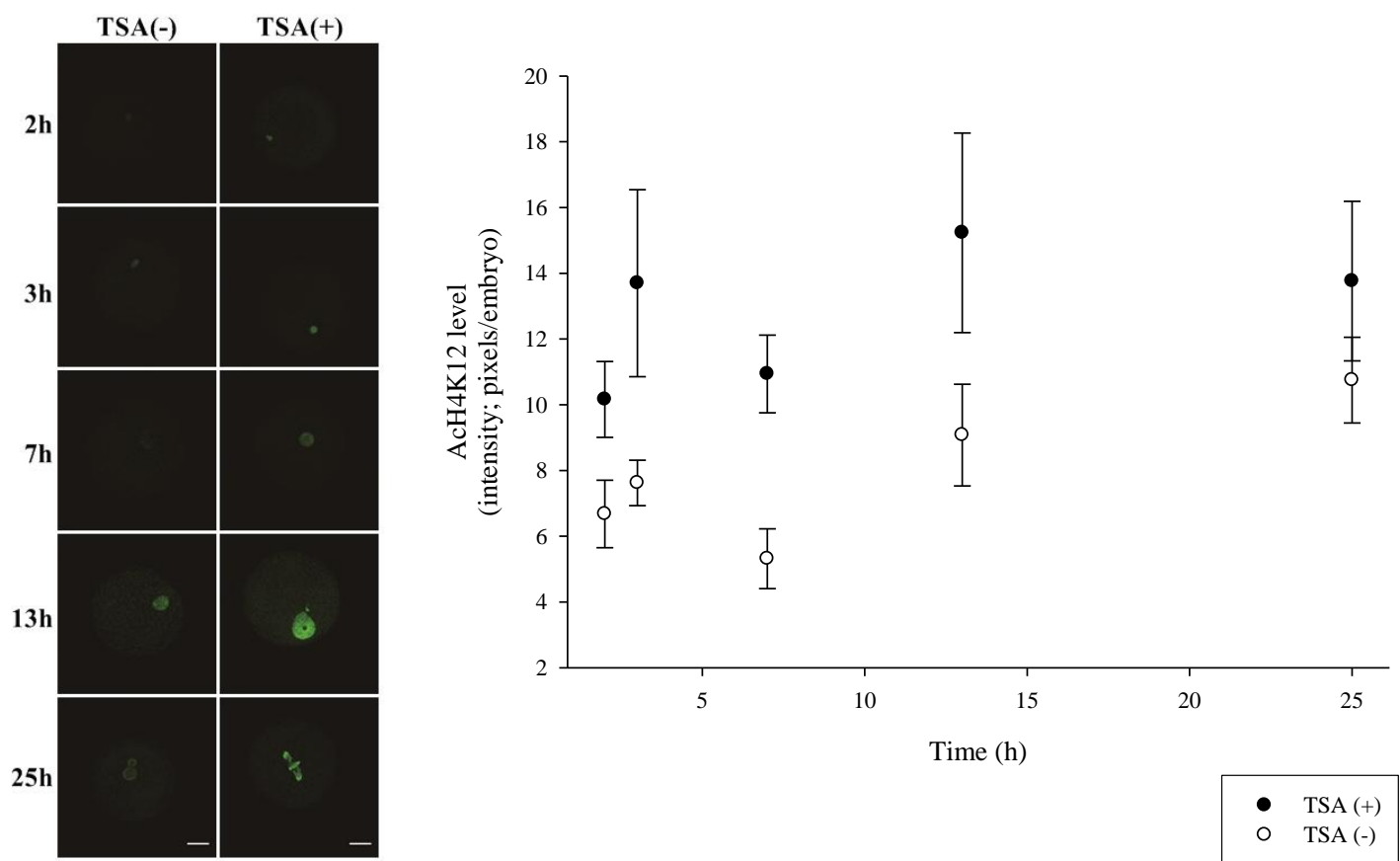

Time (h)

- TSA (+)

- TSA (-)

Figure 1. Comparison of histone acetylation levels to TSA treatment $(50 \mathrm{nM}, 24 \mathrm{~h})$ and non-treatment SCNT embryos at different time slot. Embryos were examined 2, 3, 7, 13, and $25 \mathrm{~h}$ after SCNT by immunostaining with FITC-conjugated anti-acetyl-histone H3-K9/14 (A(a)) and anti-acetyl-histone H4-K12 (B(a)). Optical intensity was measured using Image-J software from National Institutes of Health (A(b), B(b)). The values are mean \pm standard error. All scale bars represent $50 \mu \mathrm{m}$.

expression levels in SCNT blastocysts treated with TSA blastocysts both with and without TSA treatment showed compared with non-treated blastocysts, but these results were not statistically significant (Figure $2 \mathrm{a}, \mathrm{b}$ ). In contrast, expression levels higher than those of in vivo blastocysts; for imprinting genes, especially H19 and NNAT, SCNT gene, were similar among groups (Figure 2c, d, and e). The 
trophoblast marker genes, cytokeratin 8 and 18, showed lower expression levels in the SCNT blastocysts compared with in vivo blastocysts. Moreover, TSA-treated blastocysts were quite similar to non-treated blastocysts (Figure 2f, g).

\section{DISCUSSION}

Epigenetic reprogramming is an indispensable process

(a)

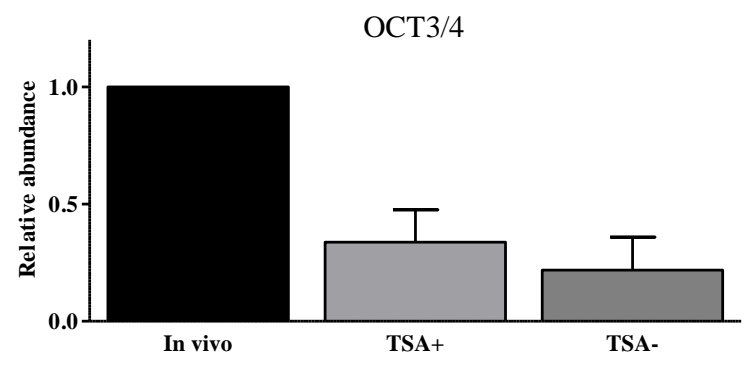

(c)

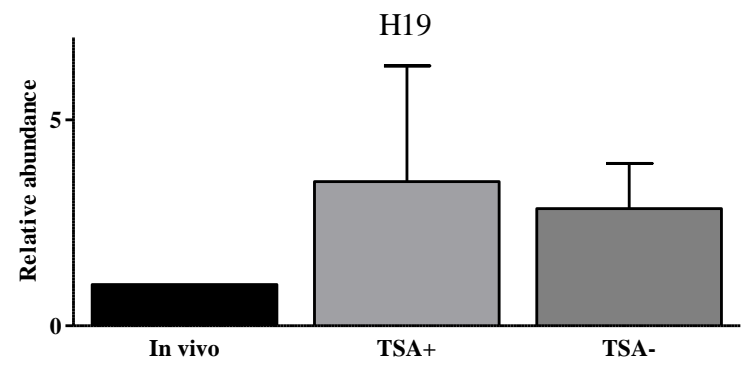

(e)

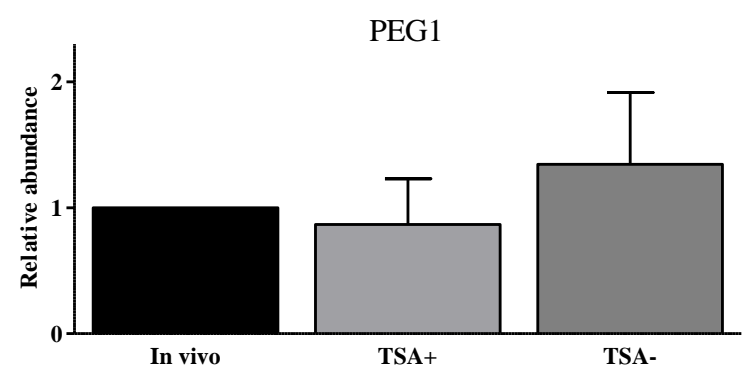

(g)

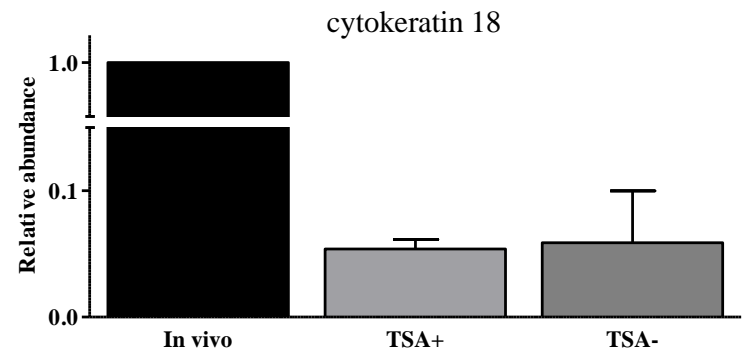

in the establishment of totipotency after fertilization, and it is known to occur abruptly in early stages of embryo development (Reik et al., 2001). Of possible epigenetic factors, global changes in DNA methylation are dramatic during pre-implantation development. DNA methylation is one of the best-characterized epigenetic markers. In the case of mice, the haploid paternal genome undergoes major asymmetric reprogramming; within $1 \mathrm{~h}$ after fertilization,

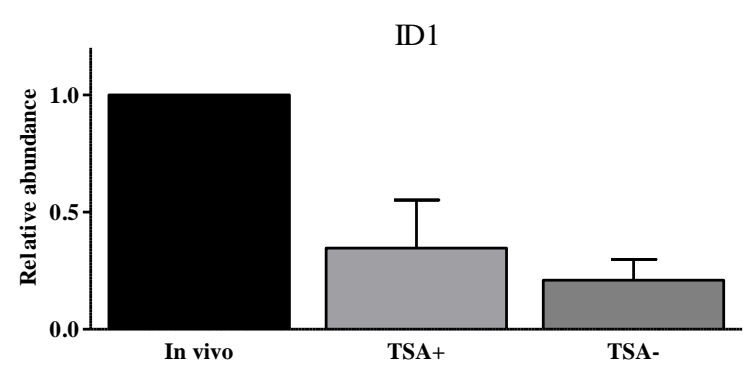

(d)

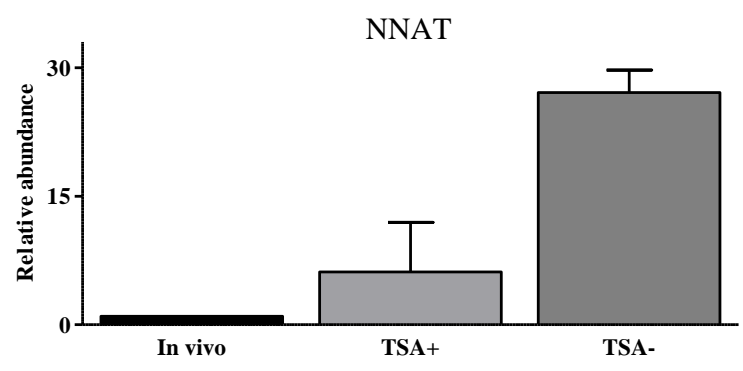

(f)

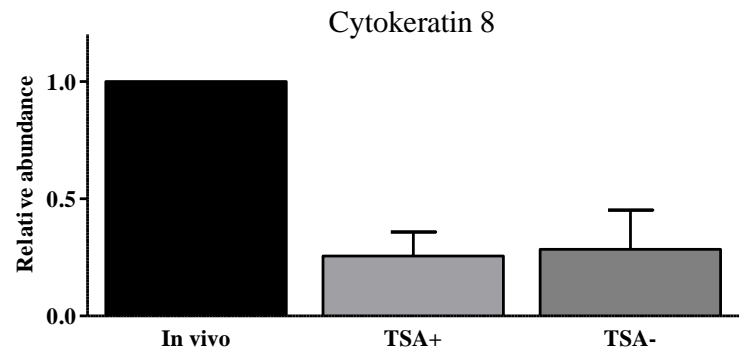

Figure 2. Expression profiles of OCT3/4 (a), ID1 (b), H19 (c), NNAT (d), PEG1 (e), cytokeratin 8 (f) and cytokeratin 18 (g) genes on in vivo embryos and SCNT treated with (+)/without (-) TSA embryos at the blastocyst stage. The relative levels of transcript were quantified using qRT-PCR and then calculated with the $2^{-\Delta \Lambda} \mathrm{Ct}$ method. Values represent mean $\pm \mathrm{SEM}(\mathrm{n}=6)$. 
active-mode demethylation occurs (Mayer et al., 2000). In contrast, the maternal genome remains highly methylated, and sequential stepwise demethylation occurs during the first cleavage division (Rougier et al., 1998).

As in the case of DNA methylation, histone acetylation that induces changes in chromatin structure is also significant for reprogramming of the genome. The global level of histone acetylation in mouse chromatin is low in oocytes both during and after meiotic metaphase, and in spermatozoa before fertilization (Adenot et al., 1997; Kim et al., 2003). Following fertilization and oocyte activation, however, the paternal genome is remodeled after replacement of its protamins with histones from the oocyte, and re-acetylation gradually initiates in the zygotic pronuclei (Spinaci et al., 2004). Furthermore, evidence for a link between DNA methylation and histone acetylation has been reported; DNA methylation, which has little effect on transcription in isolation, closely interacts with the chromatin structure that was modified by histone acetylation, so that transcription is either repressed or activated ( $\mathrm{Li}, 2002)$. To date, the precise function of histone acetylation remains open to question in mammals, but it is suggested that histone acetylation plays a critical role in resetting epigenetic patterns essential to complete transcriptional capacity during early development (Shi and Wu, 2009).

There have been reports of aberrant histone acetylation patterns in SCNT embryos, which may be the cause for the observed low developmental efficiency of SCNT (Wee et al., 2006). These aberrant patterns are derived from different remodeling process between SCNT and fertilized embryos, which are caused by different chromatin structures of somatic and germ cells, respectively. Based on these observations, researchers have attempted to regulate histone acetylation levels by using histone acetylation inhibitors such as trichostatin A (TSA). To date, positive results of TSA treatment in reconstructed embryos have been reported in mice (Kishigami et al., 2006), cows (Iager et al., 2008), and pigs (Li et al., 2008; Zhao et al., 2009). Our results also show that blastocysts formation of TSA treated SCNT embryos increased, compared to non-treated group. These results indicate that re-acetylation levels for early stage in preimplantation may affect general pre-implantation development.

Of the various histone types, acetylation of histone $\mathrm{H} 3$ is considered to play a significant role in the control of gene expression in cloned embryos and may be indispensable for their development. Histone H3 is acetylated at lysines 9, 14, 18, and 23 (Cheung et al., 2000), and histone $\mathrm{H} 4$ is acetylated at lysine 16 , lysine 8 or 12 , and lysine 5 (O'Neill and Turner, 1995). These observations suggest that acetylation of lysine 12 on histone $\mathrm{H} 4$ is a decisive epigenetic marker for gene activation (Kruhlak et al., 2001;
Smith et al., 2002). In the mouse, histone acetylation of core histones (H3K9, H3K14, and H4K16) was rapidly deacetylated following SCNT, and reacetylation occurred after activation treatment. Acetylation at the other lysine residues, $\mathrm{H} 4 \mathrm{~K} 8$ and $\mathrm{H} 4 \mathrm{~K} 12$, remained with only small deacetylation levels following SCNT (Wang et al., 2007). Acetylation of histone H4 lysin 5 (H4K5) was not observed immediately after electrofusion, but was detected in most bovine cloned embryos $3 \mathrm{~h}$ after electrofusion. Finally, cloned embryos using TSA-treated donor cells show higher acetylation levels than normal SCNT embryos (Wee et al., 2006). In the present study, AcH $3 \mathrm{~K} 9$ and AcH4K 12 signals were detected in both TSA-treated and non-treated embryos at all time points examined. However, TSA-treated groups showed an approximately two-times greater intensity compared with non-treated groups. Our results suggest that the increases in histone acetylation levels by TSA are relevant to the development of the early embryo. Moreover, modifications in chromatin structure by histone acetylation may be closely connected to DNA methylation. As additional support for the correlation between histone acetylation and DNA methylation, it was reported that treatment of round spermatid injection (ROSI) zygotes with TSA rather than with 5-azacytidine, a DNA methyltransferase inhibitor, results in significantly reduced DNA methylation level (Kishigami et al., 2006).

We further examined changes in mRNA levels for development-related genes in cloned blastocysts in response to TSA treatment. Our results showed that expression of the OCT4 gene was slightly increased in the TSA treatment group compared with the non-treated group. However, this increase was still insufficient compared with the levels observed in in vivo blastocysts. Expression levels of H19 and NNAT genes in SCNT blastocysts both with and without TSA treatment were significantly different from their in vivo counterparts. The differential expression of imprinted genes is associated with aberrant growth in SCNT embryos (Niemann et al., 2002). These results indicate that embryos displaying changes in chromatin configuration after TSA treatment may be insufficient for complete reprogramming. Moreover, previous reports have shown that methylation and the expression of imprinted genes are susceptible to in vitro culture environments during early embryo development. The possible influences of in vitro materials could not be excluded in this study. Thus, the aberrant expression of imprinted gene appears to be the result of complex effects.

Our results show that after TSA treatment, embryos at the blastocyst stage exhibit an extraordinary increase in total cell number. To determine whether the increase in total cell number is a response to TSA treatment we examined fold changes in mRNA levels of cell proliferation related genes in cloned blastocysts following TSA treatment. Our 
results showed that cytokeratin 8 and 18 were similarly transcribed in TSA treatment and non-treatment groups, whereas expression of the ID1 gene increased in the TSA treatment group as compared with the non-treated group. ID1 gene is known to be associated with cell fate determination and cell proliferation.

One of the main goals of porcine SCNT technology is to obtain a source of tailored bio-organs for transplanting to humans or to animal models for various diseases (Vodicka et al., 2005). Miniature pig cloning, particularly, is important for bio-organ studies. Intra-fallopian tube transfer procedures have been widely used as a method of embryo transfer for the production of cloned pigs because of their high efficiency. According to this method, early embryos in the 1- or 2-cell stage are transferred. Thus, our protocol of treating embryos with TSA for less than $24 \mathrm{~h}$ could be helpful for current porcine SCNT protocols by improving developmental competence.

In conclusion, it is suggested that TSA treatment in SCNT embryos can improve in vitro developmental competence, which may be attributed to histone acetylation levels. However, further studies on in vivo development are required to elucidate the potential for development to term.

\section{ACKNOWLEDGEMENTS}

This work was supported by a grant of Next-Generation BioGreen 21 Program (No. PJ00832303) Rural Development Administration, Republic of Korea.

\section{REFERENCES}

Adenot, P. G., Y. Mercier, J. P. Renard, and E. M. Thompson. 1997. Differential $\mathrm{H} 4$ acetylation of paternal and maternal chromatin precedes DNA replication and differential transcriptional activity in pronuclei of 1-cell mouse embryos. Development 124:4615-4625.

Adjaye, J., J. Huntriss, R. Herwig, A. BenKahla, T. C. Brink, C. Wierling, C. Hultschig, D. Groth, M. L. Yaspo, H. M. Picton, R. G. Gosden, and H. Lehrach. 2005. Primary differentiation in the human blastocyst: comparative molecular portraits of inner cell mass and trophectoderm cells. Stem Cells 23:1514-1525.

Armstrong, L., M. Lako, W. Dean, and M. Stojkovic. 2006. Epigenetic modification is central to genome reprogramming in somatic cell nuclear transfer. Stem Cells. 24:805-814.

Chan, H. M., M. Krstic-Demonacos, L. Smith, C. Demonacos, and N. B. La Thangue. 2001. Acetylation control of the retinoblastoma tumour-suppressor protein. Nat. Cell Biol. 3: 667-674.

Cheung, P., C. D. Allis, and P. Sassone-Corsi. 2000. Signaling to chromatin through histone modifications. Cell 103:263-271.

Hong, L., G. P. Schroth, H. R. Matthews, P. Yau, and E. M. Bradbury. 1993. Studies of the DNA binding properties of histone $\mathrm{H} 4$ amino terminus. Thermal denaturation studies reveal that acetylation markedly reduces the binding constant of the H4 "tail" to DNA. J. Biol. Chem. 268:305-314.

Horn, P. J. and C. L. Peterson. 2002. Molecular biology. Chromatin higher order folding--wrapping up transcription. Science 297:1824-1827.

Hyun, S., G. Lee, D. Kim, H. Kim, S. Lee, D. Nam, Y. Jeong, S. Kim, S. Yeom, S. Kang, J. Han, B. Lee, and W. Hwang. 2003. Production of nuclear transfer-derived piglets using porcine fetal fibroblasts transfected with the enhanced green fluorescent protein. Biol. Reprod. 69: 1060-1068.

Iager, A. E., N. P. Ragina, P. J. Ross, Z. Beyhan, K. Cunniff, R. M. Rodriguez, and J. B. Cibelli. 2008. Trichostatin A improves histone acetylation in bovine somatic cell nuclear transfer early embryos. Cloning Stem Cells 10:371-379.

Jankovic, V., A. Ciarrocchi, P. Boccuni, T. DeBlasio, R. Benezra, and S. D. Nimer. 2007. Id1 restrains myeloid commitment, maintaining the self-renewal capacity of hematopoietic stem cells. Proc. Natl. Acad. Sci. USA. 104:1260-1265.

Kim, D. H., J. Lee, K. N. Kim, H. J. Kim, H. C. Jeung, H. C. Chung, and H. J. Kwon. 2007. Anti-tumor activity of Nhydroxy-7-(2-naphthylthio) heptanomide, a novel histone deacetylase inhibitor. Biochem. Biophys. Res. Commun. 356: 233-238.

Kim, J. M., H. Liu, M. Tazaki, M. Nagata, and F. Aoki. 2003. Changes in histone acetylation during mouse oocyte meiosis. J Cell Biol. 162:37-46.

Kirchhof, N., J. W. Carnwath, E. Lemme, K. Anastassiadis, H. Scholer, and H. Niemann. 2000. Expression pattern of Oct-4 in preimplantation embryos of different species. Biol. Reprod. 63:1698-1705.

Kishigami, S., E. Mizutani, H. Ohta, T. Hikichi, N. V. Thuan, S. Wakayama, H. T. Bui, and T. Wakayama. 2006. Significant improvement of mouse cloning technique by treatment with trichostatin A after somatic nuclear transfer. Biochem. Biophys. Res. Commun. 340:183-189.

Kishigami, S., N. Van Thuan, T. Hikichi, H. Ohta, S. Wakayama, E. Mizutani, and T. Wakayama. 2006. Epigenetic abnormalities of the mouse paternal zygotic genome associated with microinsemination of round spermatids. Dev. Biol. 289:195205.

Kruhlak, M. J., M. J. Hendzel, W. Fischle, N. R. Bertos, S. Hameed, X. J. Yang, E. Verdin, and D. P. Bazett-Jones. 2001. Regulation of global acetylation in mitosis through loss of histone acetyltransferases and deacetylases from chromatin. J. Biol. Chem. 276:38307-38319.

Lee, D. Y., J. J. Hayes, D. Pruss, and A. P. Wolffe. 1993. A positive role for histone acetylation in transcription factor access to nucleosomal DNA. Cell. 72:73-84.

Lee, G. S., S. H. Hyun, H. S. Kim, D. Y. Kim, S. H. Lee, J. M. Lim, E. S. Lee, S. K. Kang, B. C. Lee, and W. S. Hwang. 2003. Improvement of a porcine somatic cell nuclear transfer technique by optimizing donor cell and recipient oocyte preparations. Theriogenology 59:1949-1957.

$\mathrm{Li}$, E. 2002. Chromatin modification and epigenetic reprogramming in mammalian development. Nat. Rev. Genet. 3:662-673.

Li, J., O. Svarcova, K. Villemoes, P. M. Kragh, M. Schmidt, I. B. Bogh, Y. Zhang, Y. Du, L. Lin, S. Purup, Q. Xue, L. Bolund, H. Yang, P. Maddox-Hyttel, and G. Vajta. 2008. High in vitro development after somatic cell nuclear transfer and trichostatin 
A treatment of reconstructed porcine embryos. Theriogenology 70: 800-808.

Luo, J., F. Su, D. Chen, A. Shiloh, and W. Gu. 2000. Deacetylation of p53 modulates its effect on cell growth and apoptosis. Nature 408:377-381.

Mann, M. R., Y. G. Chung, L. D. Nolen, R. I. Verona, K. E. Latham, and M. S. Bartolomei. 2003. Disruption of imprinted gene methylation and expression in cloned preimplantation stage mouse embryos. Biol. Reprod. 69:902-914.

Marks, P. A. 2004. The mechanism of the anti-tumor activity of the histone deacetylase inhibitor, suberoylanilide hydroxamic acid (SAHA). Cell Cycle 3:534-535.

Martinez-Balbas, M. A., U. M. Bauer, S. J. Nielsen, A. Brehm, and T. Kouzarides. 2000. Regulation of E2F1 activity by acetylation. EMBO J. 19:662-671.

Mayer, W., A. Niveleau, J. Walter, R. Fundele, and T. Haaf. 2000. Demethylation of the zygotic paternal genome. Nature 403: 501-502.

McBain, J. A., A. Eastman, C. S. Nobel, and G. C. Mueller. 1997. Apoptotic death in adenocarcinoma cell lines induced by butyrate and other histone deacetylase inhibitors. Biochem. Pharmacol. 53:1357-1368.

Medina, V., B. Edmonds, G. P. Young, R. James, S. Appleton, and P. D. Zalewski. 1997. Induction of caspase-3 protease activity and apoptosis by butyrate and trichostatin A (inhibitors of histone deacetylase): dependence on protein synthesis and synergy with a mitochondrial/cytochrome c-dependent pathway. Cancer Res. 57:3697-3707.

Mie Lee, Y., S. H. Kim, H. S. Kim, M. Jin Son, H. Nakajima, H. Jeong Kwon, and K. W. Kim. 2003. Inhibition of hypoxiainduced angiogenesis by FK228, a specific histone deacetylase inhibitor, via suppression of HIF-1alpha activity. Biochem. Biophys. Res. Commun. 300:241-246.

Munster, P. N., T. Troso-Sandoval, N. Rosen, R. Rifkind, P. A. Marks, and V. M. Richon. 2001. The histone deacetylase inhibitor suberoylanilide hydroxamic acid induces differentiation of human breast cancer cells. Cancer Res. 61: 8492-8497.

Niemann, H., C. Wrenzycki, A. Lucas-Hahn, T. Brambrink, W. A. Kues, and J. W. Carnwath. 2002. Gene expression patterns in bovine in vitro-produced and nuclear transfer-derived embryos and their implications for early development. Cloning Stem Cells 4:29-38.

O'Neill, L. P. and B. M. Turner. 1995. Histone H4 acetylation distinguishes coding regions of the human genome from heterochromatin in a differentiation-dependent but transcription-independent manner. EMBO J. 14:3946-3957.

Reik, W., W. Dean, and J. Walter. 2001. Epigenetic reprogramming in mammalian development. Science 293:1089-1093.

Rougier, N., D. Bourc'his, D. M. Gomes, A. Niveleau, M. Plachot, A. Paldi, and E. Viegas-Pequignot. 1998. Chromosome methylation patterns during mammalian preimplantation development. Genes Dev. 12:2108-2113.

Shi, L. and J. Wu. 2009. Epigenetic regulation in mammalian preimplantation embryo development. Reprod. Biol. Endocrinol. 7:59.

Shi, L. H., Y. L. Miao, Y. C. Ouyang, J. C. Huang, Z. L. Lei, J. W. Yang, Z. M. Han, X. F. Song, Q. Y. Sun, and D. Y. Chen. 2008. Trichostatin A (TSA) improves the development of rabbit- rabbit intraspecies cloned embryos, but not rabbit-human interspecies cloned embryos. Dev. Dyn. 237:640-648.

Smith, C. M., Z. W. Haimberger, C. O. Johnson, A. J. Wolf, P. R. Gafken, Z. Zhang, M. R. Parthun, and D. E. Gottschling. 2002. Heritable chromatin structure: mapping "memory" in histones H3 and H4. Proc. Natl. Acad. Sci. USA. 99 (Suppl 4):1645416461.

Spinaci, M., E. Seren, and M. Mattioli. 2004. Maternal chromatin remodeling during maturation and after fertilization in mouse oocytes. Mol. Reprod. Dev. 69:215-221.

Tao, T., A. C. Boquest, Z. Machaty, A. L. Petersen, B. N. Day, and R. S. Prather. 1999. Development of pig embryos by nuclear transfer of cultured fibroblast cells. Cloning. 1: 55-62.

Tse, C., T. Sera, A. P. Wolffe, and J. C. Hansen. 1998. Disruption of higher-order folding by core histone acetylation dramatically enhances transcription of nucleosomal arrays by RNA polymerase III. Mol. Cell. Biol. 18:4629-4638.

Turner, B. M. 2000. Histone acetylation and an epigenetic code. Bioessays 22:836-845.

Vettese-Dadey, M., P. A. Grant, T. R. Hebbes, C. Crane- Robinson, C. D. Allis, and J. L. Workman. 1996. Acetylation of histone $\mathrm{H} 4$ plays a primary role in enhancing transcription factor binding to nucleosomal DNA in vitro. EMBO J. 15:2508-2518.

Vodicka, P., K. Smetana, Jr., B. Dvorankova, T. Emerick, Y. Z. Xu, J. Ourednik, V. Ourednik, and J. Motlik. 2005. The miniature pig as an animal model in biomedical research. Ann. NY Acad. Sci. 1049:161-171

Vogelauer, M., L. Rubbi, I. Lucas, B. J. Brewer, and M. Grunstein. 2002. Histone acetylation regulates the time of replication origin firing. Mol. Cell. 10:1223-1233.

Wang, F., Z. Kou, Y. Zhang, and S. Gao. 2007. Dynamic reprogramming of histone acetylation and methylation in the first cell cycle of cloned mouse embryos. Biol. Reprod. 77: 1007-1016.

Wee, G., D. B. Koo, B. S. Song, J. S. Kim, M. J. Kang, S. J. Moon, Y. K. Kang, K. K. Lee, and Y. M. Han. 2006. Inheritable histone $\mathrm{H} 4$ acetylation of somatic chromatins in cloned embryos. J. Biol. Chem. 281:6048-6057.

Yoshida, M. and T. Beppu. 1988. Reversible arrest of proliferation of rat 3 Y1 fibroblasts in both the G1 and G2 phases by trichostatin A. Exp. Cell Res. 177:122-131.

Yoshida, M., S. Nomura, and T. Beppu. 1987. Effects of trichostatins on differentiation of murine erythroleukemia cells Cancer Res. 47:3688-3691.

Zhao, J., Y. Hao, J. W. Ross, L. D. Spate, E. M. Walters, M. S. Samuel, A. Rieke, C. N. Murphy, and R. S. Prather. 2010. Histone deacetylase inhibitors improve in vitro and in vivo developmental competence of somatic cell nuclear transfer porcine embryos. Cell Reprogram. 12:75-83.

Zhao, J., J. W. Ross, Y. Hao, L. D. Spate, E. M. Walters, M. S. Samuel, A. Rieke, C. N. Murphy, and R. S. Prather. 2009. Significant improvement in cloning efficiency of an inbred miniature pig by histone deacetylase inhibitor treatment after somatic cell nuclear transfer. Biol. Reprod. 81:525-530.

Zhao, J., J. Whyte, and R. S. Prather. 2010. Effect of epigenetic regulation during swine embryogenesis and on cloning by nuclear transfer. Cell Tissue Res. 341:13-21. 